\title{
DEGRADATION OF VETERINARY ANTIBIOTICS FROM SLAUGHTERHOUSE WASTEWATER USING TITANIUM DIOXIDE AS A CATALYST
}

\author{
MARTHA N. CHOLLOM ${ }^{1}$, SUDESH RATHILAL ${ }^{1}$, FEROZ M. SWALAHA ${ }^{1} \&$ BABATUNDE F. BAKARE ${ }^{2}$ \\ ${ }^{1}$ Durban University of Technology, South Africa \\ ${ }^{2}$ Mangosuthu University of Technology, South Africa
}

\begin{abstract}
Antibiotics (ABs) and other pharmaceuticals are designed to be effectively bioactive against certain human and animal pathogens. It has been confirmed that some of these compounds are metabolized in animals by up to $90 \%$ or more, while others are metabolized by $10 \%$ or less. The residues find their way into the environment. Titanium dioxide $\left(\mathrm{TiO}_{2}\right)$ has been extensively applied as a catalyst under UV/solar irradiation to degrade antibiotics due to the advantages it offers. The study presented here evaluated the use of $\mathrm{TiO}_{2}$ as a catalyst for the degradation of three antibiotics; namely; ciprofloxacin, enrofloxacin and sulfamethazine. Response surface methodology was used for the optimisation and modelling of independent variables, namely $\mathrm{TiO}_{2}$ dosage, antibiotics concentration and $\mathrm{pH}$, based on the Box-Behnken (BB) experimental design. Photodegradation of three veterinary antibiotics was shown to be effective using $\mathrm{TiO}_{2}$ as a catalyst. The degradation of antibiotics depended on the chosen variables. The results from the experiment were fitted into the polynomial equation which was used to further elaborate optimisation. The value of determination of coefficient $R^{2}$ were above 0.9 for $R_{1}$ and $\mathrm{R}_{2}$ and above 0.6 for $\mathrm{R}_{3}$, thus verifying the model fitting. Finally, the optimum conditions for the degradation of the selected antibiotics were obtained which were $\mathrm{R} 1 ; \mathrm{pH}$ (3-5), antibiotics concentration $(10-25 \mathrm{mg} / \mathrm{L}) . \mathrm{R} 2 ; \mathrm{pH}(3-4)$ and antibiotics concentration $(30-50 \mathrm{mg} / \mathrm{L})$ and finally $\mathrm{R} 3$; $\mathrm{pH}(10)$ and antibiotics concentration of $15 \mathrm{mg} / \mathrm{L}$.
\end{abstract}

Keywords: antibiotics, optimization, photocatalysis, antibiotic resistant strains, response surface methodology.

\section{INTRODUCTION}

There are different routes through which emerging contaminants could reach the environment. The wastewater water treatment plants (WWTPs) have been identified as one of those [1]. Conventional methods of treating wastewaters are employed for most WWTPs. The problem however is the inability of these conventional processes to completely remove these emerging micro-pollutants [2]. Effluents discharged into the environment therefore still contain some of the contaminants. Once in the environment, they disrupt the evolution of the microbial community structure, and hereafter impact on the ecological function of the water system [3]. The risk analysis of these contaminants has shown their negative impacts on the environment, such as development of antibiotics resistant bacterial and anti-resistant genes, both said to be associated with risk to human and animals [4]. Alternative methods of treatment such as advanced oxidation processes (AOPs) have shown to be able to deal with this kind of contaminants [2], [5]. AOPs reactions are based on the production of hydroxide radicals $\left({ }^{\circ} \mathrm{OH}\right)$ which are produced in the first step of the reaction. The produced radicals have strong oxidizing and disrupting properties thus reacting with complex organic molecules under the right conditions converting them into simpler compounds; carbon dioxide and water [2], [6].

Amongst the AOPs, heterogeneous photocatalysis that uses semi-conductors as catalysts are titanium dioxide, zinc oxide, iron (II) oxide, cadmium sulphide, gallium phosphide and zinc sulfide $\left(\mathrm{TiO}_{2}, \mathrm{ZnO}, \mathrm{Fe}_{2} \mathrm{O}_{3}, \mathrm{CdS}, \mathrm{GaP}\right.$ and $\left.\mathrm{ZnS}\right)$. They have been widely studied in the 
mineralisation of recalcitrant substances into readily biodegradable substances [7]. $\mathrm{TiO}_{2}$, as a semi-conductor has received the greatest interest due to the fact that it is the most active photocatalyst under the photon energy of $300 \mathrm{~nm}<1<390 \mathrm{~nm}$ and remains stable after the repeated catalytic cycles. Furthermore, $\mathrm{TiO}_{2}$ has been promoted for usage due to its ability to be biologically and chemically inert and thermally stable. It is not toxic and inexpensive [7], [8]. The combination of AOP with other treatment process such as biological system has been considered to be more economical, where AOP are used as pre-treatment or post treatment depending on the objective [2].

The study presented here aimed to evaluate the use of $\mathrm{TiO}_{2}$ as a catalyst for the degradation of antibiotics in synthetic wastewater. The one factor-at-a-time (OFAT) approach has been the focused of most studies. In OFAT studies, each factor is studied independently while keeping other factors constant and therefore does not take interactions between factors into account [9]. The response surface methodology (RSM) based on Box-Behnken statistical experiment design offers the advantage of studying the interaction between variables. Therefore in this study, it was used to optimize independent variables, namely $\mathrm{TiO}_{2}$ dosage, antibiotics concentration and $\mathrm{pH}$. Three veterinary antibiotics (ciprofloxacin, enrofloxacin and sulfamethazine) were selected based on the high usage in veterinary [10], [11].

\section{EXPERIMENT AND METHODS}

\subsection{Chemicals}

Veterinary antibiotics standards were purchased from Sigma-Aldrich. Titanium Dioxide $\left(\mathrm{TiO}_{2}\right)$ was obtained from Huntsman Tioxide South Africa, properties of the $\mathrm{TiO}_{2}$ used could be found in the work of Dlamini [12]. For $\mathrm{pH}$ adjustment, sulfuric acid $\left(\mathrm{H}_{2} \mathrm{SO}_{4}\right)$ and hydrochloric acid $(\mathrm{HCl})$ were used, purchased from Merck. All chemicals used were of analytical and HPLC grades and ultrapure water was used in the analysis. Individual stock standard solutions were prepared and stored at $4^{\circ} \mathrm{C}$. Working solutions were thereafter prepared from the stock solutions, prior to use, glassware was properly washed.

\subsection{Analytical method using HPLC}

Antibiotics concentrations were monitored using an ultrafast high-performance liquid chromatography (UHPLC) using an SPD-M20A-Photodiode Array detector (PDA) (Shimadzu) incorporating a Gemini C-18 column $(150 \times 4.6 \mathrm{~mm} \times 5 \mu \mathrm{m})$ from Phenomenex. The mobile phase was a mixture of A (water with $0.1 \%$ formic acid) and B (acetonitrile with $0.1 \%$ formic acid). A simple isocratic method was employed consisting of $15 \%$ of $\mathrm{B}$, run time of 15 minutes. The sample injection volume was $10 \mu \mathrm{L}$ at a flowrate of $1 \mathrm{ml} / \mathrm{min}$. The $\mathrm{pH}$ was measured using Orion $\mathrm{pH}$ meter.

\subsection{Photodegradation experiments}

Photodegradation experiments on antibiotic aqueous solutions were carried out using 10, 30 and $50 \mathrm{mg} / \mathrm{L}$ of the stock solution in distilled water first to ascertain their biodegradability (data not shown) and thereafter in the synthetic wastewater was used emulating that from a slaughterhouse. Experiments were carried out in beakers, the beakers were lined with foils to avoid direct exposure to light and thereafter filled with the solution to be degraded, and $\mathrm{pH}$ adjusted, then beakers were covered with a box. The right amounts of $\mathrm{TiO}_{2}$ were measured and added to the solution. Suspension of the $\mathrm{TiO}_{2}$ particles was ensured by using a stirrer to continuously stir, and after 30 mins samples were taken to determine the effect of adsorption 
of the antibiotics. After that, the foils were taken off the beakers. UV-A irradiation was provided by two $9 \mathrm{~W}$ lamp emitting predominantly at 350-400 nm each. The lamps were suspended above the beakers to enable the photodegradation of the contaminants [13]. Samples were collected at the set intervals using a syringe and filtered through a $0.22 \mu \mathrm{m}$ nylon syringe filter for determination of antibiotic concentration by UHPLC. Adsorption studies were carried out in the dark. No significant removal was observed, data not shown. Therefore, this indicated that the degradation pathway was mostly by photodegradation.

The degradation efficiency was evaluated as follows in eqn (1):

$$
E=C o-\frac{C_{t}}{C_{t}} \times 100
$$

where $C_{o}$ initial concentration and $C_{t}$ is the concentration at the time of withdrawal.

\subsection{Design of experiments}

Response surface methodology (RSM) based on Box-Behnken design (BBD) is a useful statistical technique for modelling and the optimization. The design was applied for a threelevel variable on the response function, thus giving a minimum number of experiment. Further details about the application of the BBD and the advantages it presents can be found in the work by [14]. Table 1 shows the experimental design inputs and factors, three independent variables were used and codified for low, centre and high levels $(-1,0,+1)$. The ranges of the variables and experimental conditions are shown further in Table 1.

Input variables were coded according to eqn (2) [14]:

$$
X n=\frac{\mathrm{xn}-\mathrm{xo}}{\Delta x n},
$$

where $\mathrm{Xn}, \mathrm{xn}$, xo and $\Delta x n$ represent the coded level, the real value, the centre point value and the variable step change respectively.

Regression analysis and optimization were performed using Design Expert v.11.0.0 software (Stat-Ease Inc., USA). A second order polynomial eqn (3) was used to describe the effect of the chosen parameters and their interactions on the responses using the BBD for the experimental design

$$
Y i=\beta o+\sum_{i=1}^{k} \beta i X i+\sum_{i=1}^{k} \beta i i X i^{2}+\sum_{j=1}^{k-1} \beta i j X i X j+C,
$$

where $\beta_{o}, \beta_{i}, \beta_{i i}$, and $\beta_{i j}$ are constant, linear, quadratic, and cross factor interaction coefficients, respectively; $X_{i}$ and $X_{j}$ represent the independent variables; $Y_{i}$ is predicted response; and $k$ and $c$ are the number of factors and the residual terms, respectively. The significance of the model equations, individual parameters and factor interaction were evaluated by analysis of variance (ANOVA) at the confidence intervals (CI) of $95 \%$ ( $\alpha=$ $0.05)$. Two-dimensional (2D) contour plots and three-dimensional (3D) surface responses were obtained in the quadratic models.

Table 1: Experimental design inputs and factors.

\begin{tabular}{|l|c|c|c|}
\hline & \multicolumn{3}{|c|}{ Levels $(\mathrm{X})$} \\
\hline Input variables & -1 & 0 & 1 \\
\hline X1:Catalyst loading $(\mathrm{g} / \mathrm{L})$ & 0.5 & 1 & 1.5 \\
\hline X2:Contaminant conc. $(\mathrm{mg} / \mathrm{L})$ & 10 & 30 & 50 \\
\hline X3:pH & 3 & 6 & 10 \\
\hline
\end{tabular}




\section{RESULTS AND DISCUSSION}

\subsection{Statistical analysis}

The measured responses were photocatalytic degradation of the three antibiotics. The B-B design and percentage of degradation of the antibiotics are listed in Table 2. The catalyst dosage varied from 0.5 to $1.5 \mathrm{~g} / \mathrm{L}$ while working concentration of the antibiotics was $10-50$ $\mathrm{mg} / \mathrm{L}$. Finally, $\mathrm{pH}$ of 3, 6 and 10 were investigated. The concentration of antibiotics values was above the limit that is usually found in the wastewater streams, various researchers have used similar and higher concentrations based on the following reasons; the assessment of the process efficiency within a given time and for the accurate determination of the residual antibiotics that will not be degraded [15].

Experimental runs were carried out based on the BBD matrix generated as shown in Table 2. Based on the statistical analysis, significant variables and their responses were selected. $\mathrm{pH}$ was found to have a great influence on the studied antibiotics, the reason for this was attributed to the physiochemical properties of the antibiotics.

Table 2: B-B design matrix in actual units and responses for antibiotics degradation.

\begin{tabular}{|c|c|c|c|c|c|c|}
\hline \multirow{2}{*}{ Run } & Factor 1 & Factor 2 & Factor 3 & \multicolumn{3}{|c|}{ Degradation (responses) } \\
\hline \multirow{2}{*}{ A:pH } & $\begin{array}{c}\text { B:ABs } \\
\text { conc. }\end{array}$ & $\begin{array}{c}\text { C:Catalyst } \\
\text { loading }\end{array}$ & Cipro. & Enro. & Sulfa. \\
\cline { 3 - 7 } & $\mathrm{mg} / \mathrm{L}$ & $\mathrm{g} / \mathrm{L}$ & $\%$ & $\%$ & $\%$ \\
\hline 2 & 6.5 & 10 & 0.5 & 68.38 & 67.29 & 79.39 \\
\hline 3 & 10 & 30 & 1 & 62.20 & 67.63 & 89.54 \\
\hline 4 & 10 & 10 & 1.5 & 60.48 & 65.15 & 87.04 \\
\hline 5 & 6.5 & 30 & 1.5 & 71.61 & 67.94 & 87.38 \\
\hline 6 & 3 & 30 & 1.5 & 71.61 & 67.94 & 87.38 \\
\hline 7 & 6.5 & 30 & 1.5 & 71.61 & 67.94 & 87.38 \\
\hline 8 & 3 & 30 & 0.5 & 68.85 & 64.81 & 86.41 \\
\hline 9 & 6.5 & 30 & 1.5 & 71.61 & 67.94 & 87.38 \\
\hline 10 & 6.5 & 50 & 1 & 67.09 & 68.99 & 80.50 \\
\hline 11 & 6.5 & 30 & 1.5 & 71.61 & 67.94 & 87.38 \\
\hline 12 & 10 & 50 & 1.5 & 63.93 & 70.11 & 82.61 \\
\hline 13 & 6.5 & 50 & 0.5 & 76.38 & 67.29 & 83.39 \\
\hline 14 & 6.5 & 10 & 1 & 76.13 & 66.89 & 84.82 \\
\hline 15 & 3 & 30 & 1 & 77.38 & 68.17 & 87.34 \\
\hline 16 & 3 & 10 & 1.5 & 86.59 & 68.20 & 84.75 \\
\hline 17 & 10 & 30 & 0.5 & 75.39 & 70.61 & 87.81 \\
\hline
\end{tabular}


Polynomial equations for the $\mathrm{r}$ responses consisting of 7, 8 and 9 coefficients respectively were obtained from the ANOVA table. These are represented in eqns (4)-(6)

$$
\begin{gathered}
\mathrm{Y}_{1}=39.5+2.77 \mathrm{~A}+0.17 \mathrm{~B}+62.3 \mathrm{C}+0.07 \mathrm{AB}-6.4 \mathrm{AC}-0.85 \mathrm{BC}-0.065 \mathrm{~A}^{2}, \\
\mathrm{Y}_{2}=60.38+1.24 \mathrm{~A}-0.16 \mathrm{~B}+9.07 \mathrm{C}+0.02 \mathrm{AB}-1.86 \mathrm{AC}+0.10 \mathrm{BC}, \\
\mathrm{Y}_{3}=67.08-0.87 \mathrm{~A}+1.05 \mathrm{~B}+12.65 \mathrm{C}-0.003 \mathrm{AB}+0.39 \mathrm{AC}-0.41 \mathrm{BC}+0.071 \mathrm{~A}^{2}-0.012 \mathrm{~B}^{2} .
\end{gathered}
$$

$\mathrm{Y}_{1}, \mathrm{Y}_{2}$ and $\mathrm{Y}_{3}$ are the degradation efficiencies, while $\mathrm{A}, \mathrm{B}$ and $\mathrm{C}$ represent the coded values for $\mathrm{pH}$, antibiotic concentration and catalyst loading respectively. Polynomial eqns (2) and (4) generated were quadratic equations while polynomial eqn (3) was a two-factor interaction model. A negative or positive sign before each term represents antagonistic or synergistic effects of the term on antibiotics degradation efficiency, respectively [16]. The polynomial eqns (2)-(4) showed that the catalyst loading (C) had a synergistic effect on all the responses when compared to other variables. With regards to the response in $\mathrm{Y} 3, \mathrm{pH}$ seemed to have a negative influence when in acidic media in terms of the response of the degradation of sulfamethazine while reverse was observed if the medium was alkaline. To increase the responses, the terms which had significant effects are as shown below:

$$
\mathrm{Y}_{1}=\mathrm{C}>\mathrm{A}>\mathrm{B}>\mathrm{BC}>\mathrm{AC} ; \mathrm{Y}_{2}=\mathrm{C}>\mathrm{A}>\mathrm{BC}>\mathrm{AB}>\mathrm{B}>\mathrm{AC} ; \mathrm{Y}_{3}=\mathrm{C}>\mathrm{B}>\mathrm{AC}>\mathrm{AB}>\mathrm{A} \text {. }
$$

To further buttress the interaction of factors and models generated, data were described in the ANOVA table, Table 3. According to results of the ANOVA presented in Table 3, the degradation of the all the antibiotics were affected by the synergistic effects of the mostly the catalyst loading (C) wastewater $\mathrm{pH}(\mathrm{A})$ antibiotics concentration (B) and the interaction between antibiotics concentration and the initial catalyst loading $(C)$. It shows the Fisher $(F)$ and probability $(P)$ values. They were tools used to determine the significant variables. A high Fisher's $F$ value and a very low probability $P$ value indicated significance of the results [9]. $P$ values lower than 0.05 indicated their significance while $P$ values greater than 0.05 indicated their insignificance on the degradation of the antibiotics. The $F$ and $P$ values obtained are shown in Table 3. High $F$ values were obtained for all the antibiotics degraded as seen represented as R1 (Ciprofloxacin) R2 (Enrofloxacin) and R3 (Sulfamethazine). The $p$ values for responses $\mathrm{R}_{1}$ and $\mathrm{R}_{2}$ were $<0.0001$, for all the inputted variables. However, $\mathrm{R}_{3}$ had $p$ values of $<0.0001,<0.0008$ and $<0.7782$, thus indicating that catalyst loading had an antagonistic effect on the response. However, on a general note, $P$ values were within the required $p$ range.

Similarly, the fit of the polynomial was also expressed as the coefficient of determination $\mathrm{R}^{2}$ and the adjusted $\mathrm{R}^{2}$. The $\mathrm{R}^{2}$ defines the overall performance of the model and for quality check, it is purposed that it should be close to 1 [16]. The $\mathrm{R}^{2}$ values for the responses were $0.9984,0.9094,0.9964$ for the adjusted while for the predicted, they were; 0.9954, 0.6431, 0.9701 . For all responses, we observed an interaction between the variables, with catalyst loading having greater effect on all the responses.

\subsection{Response surface and optimisation}

The graphical representation of the response models forms the basis of the RSM to visualize the effects of the interactions [16]. The graphical representation of the reliabilities of the models developed are shown in the diagnostic plots as the predicted vs the actual for the responses in Figs 1-3(a). In those plots it is expected that the points plotted should be aligned on the on the straight line, thus an indication of the significance of the developed model on the response. 
Table 3: Regression analysis of the terms of the predicted model.

\begin{tabular}{|c|c|c|c|c|c|c|}
\hline & \multicolumn{3}{|c|}{ F-value } & \multicolumn{3}{|c|}{ p-value } \\
\hline Source & R 1 & R 2 & R 3 & R 1 & R 2 & R 3 \\
\hline Model & 1390.66 & 27.76 & 556.55 & $<0.0001$ & $<0.0001$ & $<0.0001$ \\
\hline A-pH & 4703.68 & 54.29 & 88.59 & $<0.0001$ & $<0.0001$ & $<0.0001$ \\
\hline $\begin{array}{l}\text { B-ABs } \\
\text { concentration }\end{array}$ & 1976.18 & 22.30 & 1019.47 & $<0.0001$ & 0.0008 & $<0.0001$ \\
\hline $\begin{array}{l}\text { C-Catalyst } \\
\text { loading }\end{array}$ & 248.12 & 0.0837 & 172.67 & $<0.0001$ & 0.7782 & $<0.0001$ \\
\hline $\mathrm{AB}$ & 1706.22 & 31.86 & 8.12 & $<0.0001$ & 0.0002 & 0.0215 \\
\hline $\mathrm{AC}$ & 2894.26 & 80.55 & 21.15 & $<0.0001$ & $<0.0001$ & 0.0018 \\
\hline $\mathrm{BC}$ & 1660.26 & 8.26 & 763.82 & $<0.0001$ & 0.0166 & $<0.0001$ \\
\hline $\mathrm{A}^{2}$ & 39.33 & & 90.40 & 0.0001 & & $<0.0001$ \\
\hline $\mathrm{B}^{2}$ & & & 2858.82 & & & $<0.0001$ \\
\hline \multicolumn{4}{|c|}{ Fit Statistics } & & & \\
\hline Std. Dev. & 0.2551 & 0.4456 & 0.1832 & & & \\
\hline Mean & 70.65 & 67.24 & 84.88 & & & \\
\hline C.V. \% & 0.3610 & 0.6628 & 0.2159 & & & \\
\hline $\mathrm{R}^{2}$ & 0.9991 & 0.9434 & 0.9982 & & & \\
\hline Adjusted $\mathrm{R}^{2}$ & 0.9984 & 0.9094 & 0.9964 & & & \\
\hline Predicted $\mathrm{R}^{2}$ & 0.9954 & 0.6431 & 0.9701 & & & \\
\hline Adeq Precision & 147.5851 & 20.7713 & 76.9370 & & & \\
\hline
\end{tabular}

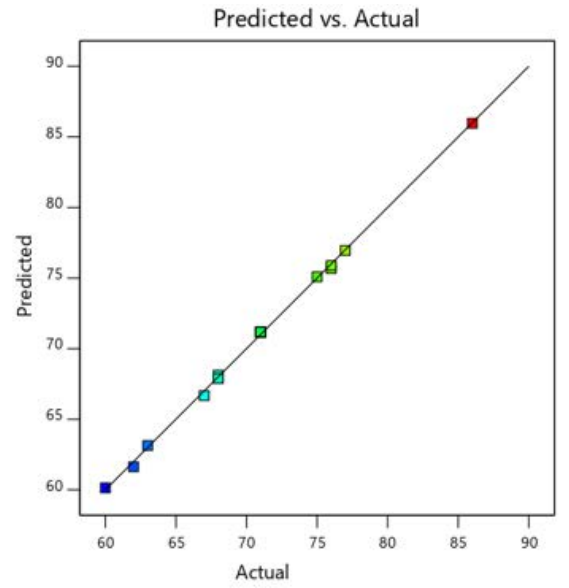

(a)

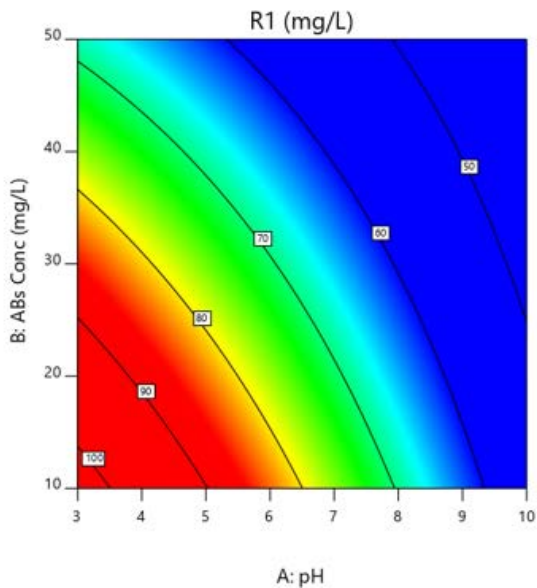

(b)

Figure 1: (a) The diagnostic plot of predicted versus actual for the degradation of response Ciprofloxacin (R1); (b) The 3D plots for R1 response model at $\mathrm{pH}$ vs antibiotics concentration at a catalyst loading of $1.5 \mathrm{~g} / \mathrm{L}$. 
Therefore, from Figs 1(a) and 3(a), it was observed that most of the points were aligned on the straight line for the developed models for R1 and R3, thus indicating the significance of the model developed, based on the input variables. However, in Fig. 2(a), the points were a little further away from the straight line.

Thus, signifying that not all the levels of input variables had a significant effect on the response (R2). However, taking the standard deviation between the predicted and the actual into account for the all the models developed, including that of R2, it was observed that following values emerged for $0.255,0.445$ and 0.1832 as the standard deviations for all the models. These values were below $5 \%$.

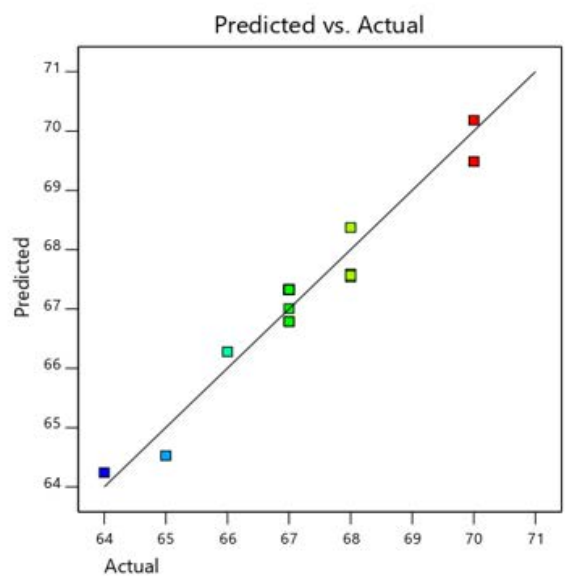

(a)

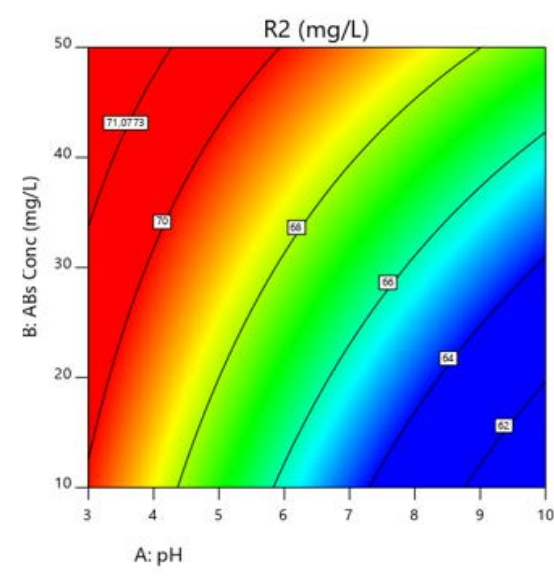

(b)

Figure 2: (a) The diagnostic plot of predicted versus actual for the degradation of response Enrofloxacin (R2); (b) The 3D plots for R2 response model at $\mathrm{pH}$ vs antibiotics concentration at a catalyst loading of $1.5 \mathrm{~g} / \mathrm{L}$.

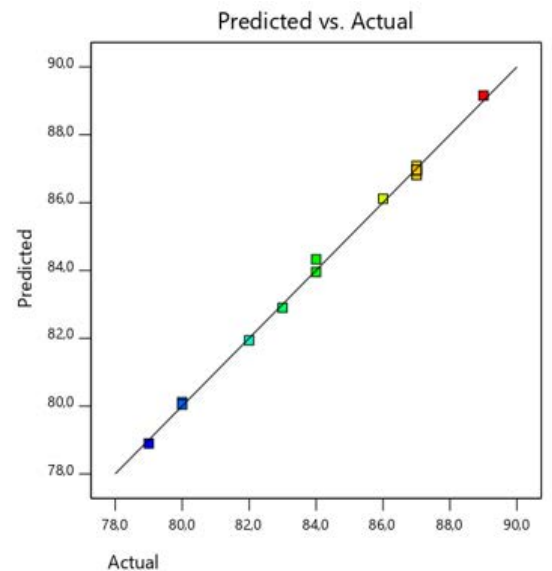

(a)

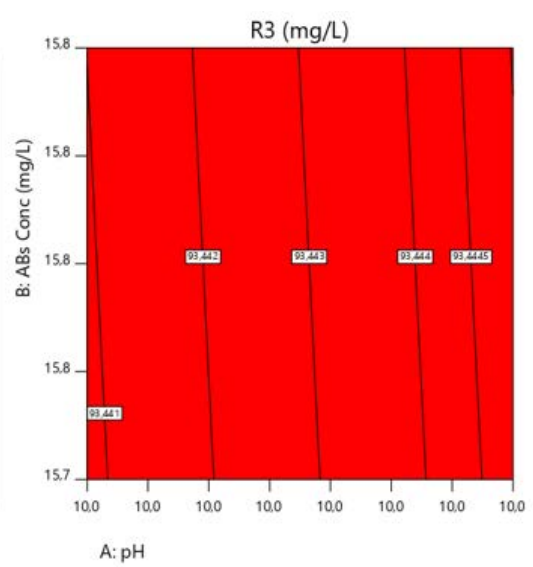

(b)

Figure 3: (a) The diagnostic plot of predicted versus actual for the degradation of response Sulfamethazine (R3); (b) The 3D plots for R3 response model at $\mathrm{pH}$ vs antibiotics concentration at a catalyst loading of $1.5 \mathrm{~g} / \mathrm{L}$. 
Figs 1 and 2(b) shows the 3D contour plots for all the responses. They represent the surface area to observe the plot within which the process performs at optimal level due to the effects of the interaction of the factors in consideration. For all the responses, it was observed that the catalyst loading was held at a constant at while the $\mathrm{pH}$ and the antibiotics concentration changed. The optimal regions for $\mathrm{R} 1$ were found to be $\mathrm{pH}(3-5)$, antibiotics concentration (10-25 mg/L). R2 values were; $\mathrm{pH}(3-4)$ and antibiotics concentration (30-50 $\mathrm{mg} / \mathrm{L})$. Finally for R3; $\mathrm{pH}(10)$ and antibiotics concentration of $15 \mathrm{mg} / \mathrm{L}$. This suggest that the degradation of R1 and R2 were effective at acidic medium. From Figs 1 and 2(b) it was noticed that increasing the $\mathrm{pH}$ of the medium for 3 to 10 , the degradation reduced from $100 \%$ for R1 to $50 \%$ while for R2 it reduced from $71 \%$ to $62 \%$. However, with respect to R3, the alkaline region was favoured at $\mathrm{pH}$ for R3. Observable in Fig. 3(b) it is noticed that only $\mathrm{pH}$ 10 was displayed in the contour plot. Degradability was $93-94 \%$. With regards to the degradability of the antibiotics; Ciprofloxacin was less biodegradable at as compared to other two antibiotics.

The effect of catalyst loading was enhanced on all the variables, were an increase in the catalyst loading gave an increase in the degradation of the antibiotics, reason was said to be due increased $\mathrm{OH}$ production. However, it worthy to note that increasing the catalyst loading above the optimum could decrease the degradation rate due to the fact that UV light penetration may decrease due to increased turbidity [17]. The optimum catalyst loading of $1.5 \mathrm{~g} / \mathrm{L}$ is agreement with that found by Moosavi and Tavakoli [9].

The significant effect of $\mathrm{pH}$ on all the measured variables could be explained by the properties of both the antibiotics and the catalyst itself. Studies have revealed that the point of zero charge $\left(\mathrm{pH}_{\mathrm{PZC}}\right)$ for $\mathrm{TiO}_{2}$ is 6.25 [9]. Again, the three antibiotics used displayed different ionization stages owing to their various ionisable functional groups, please see Gimeno et al. [2]; De Bel et al. [18] and Abellán et al. [19] for further information on the $\mathrm{pK}_{\mathrm{a}}$ values of the antibiotics used.

Degradation of Ciprofloxacin at low $\mathrm{pH}$ as obtained in this study agrees with other studies, for example, degradation at $\mathrm{pH} 3$ was found to be four times faster than at $\mathrm{pH} 7$ [18]. The possible explanation given for this was that degradation was clearly faster when the main part of the ciprofloxacin molecules carried an overall positive charge, the positively charged molecules were then said to be accumulated at the negatively charged liquid-bubble interface and as well where the concentration of the reactive radicals and temperature were higher during the study [18].

\section{CONCLUSION}

Photodegradation of three veterinary antibiotics was shown to be effective using $\mathrm{TiO}_{2}$ as a catalyst. Photodegradation depended on the several variables such as catalyst loading, $\mathrm{pH}$ of the solution and the initial antibiotics concentration. Response surface methodology was used for optimisation and modelling which was based on the Box-Behnken (BB). The results from the experiment were fitted into the polynomial equation which was used to further elaborate optimisation. The value of determination coefficient R2 were above 0.9 for R1 andR2 and above 0.6 for R3, thus verifying the model fitting. Finally, the optimum conditions for the degradation of the selected antibiotics were obtained which were $\mathrm{R} 1$; $\mathrm{pH}(3-5)$, antibiotics concentration (10-25 mg/L). R2; $\mathrm{pH}(3-4)$ and antibiotics concentration (30-50 mg/L) and finally R3; pH (10) and antibiotics concentration of $15 \mathrm{mg} / \mathrm{L}$. 


\section{ACKNOWLEDGEMENTS}

The authors wish to thank the Durban University of Technology and the National Research Foundation for funding this research and Mrs Devrani Naicker of the Chemistry department of Durban University of Technology for providing the assistance with the use of UPHLC.

\section{REFERENCES}

[1] Lapworth, D., Baran, N., Stuart, M.E. \& Ward, R., Emerging organic contaminants in groundwater: A review of sources, fate and occurrence. Environmental Pollution, 163, pp. 287-303, 2012. DOI: 10.1016/j.envpol.2011.12.034.

[2] Gimeno, O., García-Araya, J.F., Beltrán, F.J., Rivas, F.J. \& Espejo, A., Removal of emerging contaminants from a primary effluent of municipal wastewater by means of sequential biological degradation-solar photocatalytic oxidation processes. Chemical Engineering Journal, 290, pp. 12-20, 2016. DOI: 10.1016/j.cej.2016.01.022.

[3] Bouki, C., Venieri, D. \& Diamadopoulos, E., Detection and fate of antibiotic resistant bacteria in wastewater treatment plants: A review. Ecotoxicology and Environmental Safety, 91, pp. 1-9, 2013. DOI: 10.1016/j.ecoenv.2013.01.016.

[4] Blair, B., Nikolaus, A., Hedman, C., Klaper, R. \& Grundl, T., Evaluating the degradation, sorption, and negative mass balances of pharmaceuticals and personal care products during wastewater treatment. Chemosphere, 134, pp. 395-401, 2015. DOI: $10.1016 /$ j.chemosphere.2015.04.078.

[5] Mecha, A.C., Onyango, M.S., Ochieng, A., Fourie, C.J.S. \& Momba, M.N.B., Synergistic effect of UV-vis and solar photocatalytic ozonation on the degradation of phenol in municipal wastewater: A comparative study. Journal of Catalysis, 341, pp. 116-125, 2016. DOI: 10.1016/j.jcat.2016.06.015.

[6] Grote, B., Application of Advanced Oxidation Processes (aop) in Water Treatment, in 37th Annual Qld Water Industry Operations Workshop, Parklands: Gold Coast, pp. 17-23, 2012.

[7] Chong, M.N., Jin, B., Chow, C.W. \& Saint, C., Recent developments in photocatalytic water treatment technology: A review. Water Research, 44(10), pp. 2997-3027, 2010. DOI: $10.1016 /$ j.watres.2010.02.039.

[8] He, Y., Sutton, N.B., Rijnaarts, H.H.H. \& Langenhoff, A.A.M., Degradation of pharmaceuticals in wastewater using immobilized $\mathrm{TiO}_{2}$ photocatalysis under simulated solar irradiation. Applied Catalysis B: Environmental, 182, pp. 132-141, 2016. DOI: 10.1016/j.apcatb.2015.09.015.

[9] Moosavi, F.S. \& Tavakoli, T., Amoxicillin degradation from contaminated water by solar photocatalysis using response surface methodology (RSM). Environmental Science and Pollution Research 23(22), pp. 23262-23270, 2016. DOI: 10.1007/s11356-016-7349-y.

[10] Adamek, E., Baran, W. \& Sobczak, A., Photocatalytic degradation of veterinary antibiotics: Biodegradability and antimicrobial activity of intermediates. Process Safety and Environmental Protection, 103, pp. 1-9, 2016. DOI: 10.1016/j.psep.2016.06.015.

[11] Gelband, H. et al., The state of the world's antibiotics 2015. Wound Healing Southern Africa, 8, 30-34, 2015.

[12] Dlamini, C.P., Evaluation of Micro-Scaled $\mathrm{TiO}_{2}$ on Degradation and Recovery of $\mathrm{mTiO}_{2}$ From Treated Drinking Water, Durban University of Technology: Durban, p. $171,2016$.

[13] Amalraj Appavoo, I., Hu, J., Huang, Y., Li, S.F. \& Ong, S.L., Response surface modeling of Carbamazepine (CBZ) removal by Graphene-P25 nanocomposites/UVA 
process using central composite design. Water Research, 57, pp. 270-279, 2014. DOI: 10.1016/j.watres.2014.03.007.

[14] Tetteh, E.K., Rathilal, S. \& Chollom M.N., Pre-treatment of industrial mineral oil wastewater using response surface methodology. WIT Transactions on Ecology and the Environment, 216, pp. 181-191, 2017. DOI: 10.2495/WS170171.

[15] Dimitrakopoulou, D., Rethemiotaki, I., Frontistis, Z., Xekoukoulotakis, N.P., Venieri, D. \& Mantzavinos, D., Degradation, mineralization and antibiotic inactivation of amoxicillin by UV-A/TiO(2) photocatalysis. Journal of Environmental Management, 98, pp. 168-174, 2012. DOI: 10.1016/j.jenvman.2012.01.010.

[16] Kweinor Tetteh, E. \& Rathilal, S., Evaluation of the coagulation floatation process for industrial mineral oil wastewater treatment using response surface methodology (rsm). International Journal of Environmental Impacts: Management, Mitigation and Recovery, 1(4), pp. 491-502, 2018. DOI: 10.2495/ei-v1-n4-491-502.

[17] Elmolla, E.S. \& Chaudhuri, M., Degradation of amoxicillin, ampicillin and cloxacillin antibiotics in aqueous solution by the UV/ZnO photocatalytic process. Journal of Hazardous Materials, 173(1-3), pp. 445-449, 2010. DOI: 10.1016/j.jhazmat.2009.08.104.

[18] De Bel, E., Dewulf, J., Witte, B.D., Van Langenhove, H. \& Janssen, C., Influence of $\mathrm{pH}$ on the sonolysis of ciprofloxacin: Biodegradability, ecotoxicity and antibiotic activity of its degradation products. Chemosphere, 77(2), pp. 291-295, 2009. DOI: 10.1016/j.chemosphere.2009.07.033.

[19] Abellán, M.N., Giménez, J. \& Esplugas, S., Photocatalytic degradation of antibiotics: The case of sulfamethoxazole and trimethoprim. Catalysis Today, 144(1-2), pp. 131136, 2009. DOI: 10.1016/j.cattod.2009.01.051. 